\title{
Sexual and Asexual Reproduction in Two Populations of the Fissiparous Asteroid Coscinasterias acutispina in Toyama Bay, Japan
}

\author{
Youichi Seto $^{1)}$, Yukiko Moriyama ${ }^{2)}$, Daisuke Fujita ${ }^{1)}$ and Mieko Komatsu ${ }^{2)}$ \\ ${ }^{1)}$ Toyama Prefectural Fisheries Research Institute, Takatsuka 364, Namerikawa 936-8536, Japan \\ ${ }^{2)}$ Department of Biology, Faculty of Science, Toyama University, Gofuku 3190, Toyama 930-0887, Japan
}

\begin{abstract}
Sexual and asexual reproduction of the fissiparous asteroid Coscinasterias acutispina (Stimpson) was studied in two populations (Kurosaki and Uozu) in Toyama Bay, Sea of Japan, during April 1998 - March 1999 (Kurosaki) and April 1998 - October 1999 (Uozu). A total of 96\% and 87\% of all starfish collected at Kurosaki and Uozu, respectively, showed signs of asexual reproduction by fission. Monthly changes in the ratio of regenerated arm length to maximum arm length revealed that starfish in these populations split most frequently in summer. There was a marked difference in the development of gonads between the two populations. In the Kurosaki population, monthly changes of gonad indices and histological observations on gonads indicated a distinct annual cycle, with a winter spawning season in both males and females. In the Uozu population, gonad indices remained low, and no starfish with mature gonads were observed during the study. An unbalanced sex ratio was observed in both populations; the Uozu population was composed entirely of males. The absence of mature gonads and the extremely biased sex ratio suggest that larval recruitment was low or absent in the Uozu population.
\end{abstract}

Key words: asexual reproduction, Coscinasterias acutispina, fissiparity, sexual reproduction, starfish, Toyama Bay

\section{INTRODUCTION}

The eight-rayed asteroid Coscinasterias acutispina (Stimpson) is a fissiparous species of the Asteriidae, which is common in shallow waters of central and southern Japan (Fujita \& Seto 2000a). This species is a known predator on released juvenile abalone (Hayashi 1988; Futashima et al. 1989; Fujita \& Seto 2000b), the horned turban Turbo cornutus (Lightfoot) (Fujii 1991; Fujita \& Seto 1998) and limpets (Iwasaki 1993). This species can reproduce both asexually by fission (Yamazi 1950; T. Fujita 1999) and sexually (Noumura \& Kanatani 1962; Oguro \& Komatsu 1984). On the Pacific coast of Japan, asexual reproduction in $C$.

Received September 25, 2000: Accepted November 16, 2000 acutispina was well documented by T. Fujita (1999), who examined the population structure in Sagami Bay, and reported on the size-dependency and seasonality of fission. However, the only report on sexual reproduction by Noumura \& Kanatani (1962) states that breeding occurs from late June until early July in Sagami Bay. On the Sea of Japan side of Japan, information on reproduction of this species is limited to Oguro \& Komatsu (1984) and Fujita \& Seto (1998). The former commented that the breeding season in Toyama Bay occurs in winter, while the latter reported repeated fission during a nine-month feeding experiment using samples from the bay. There have been no detailed studies on sexual reproduction of $C$. acutispina in Japan or on asexual reproduction on the Sea of Japan side of Japan. In the present study, two populations of C. acutispina in Toyama Bay were monitored to follow sexual and asexual reproduction. 


\section{MATERIALS AND METHODS}

Specimens of C. acutispina were collected at two sites in Toyama Bay, Kurosaki $\left(36^{\circ} 58^{\prime} \mathrm{N}, 137^{\circ} 03^{\prime} \mathrm{E}\right)$ and Uozu ( $36^{\circ} 49^{\prime} \mathrm{N}, 137^{\circ} 23^{\prime} \mathrm{E}$ ) on the Sea of Japan side of central Japan. Kurosaki is located on a rocky coast in the inner part of the bay, while Uozu is located on a stony coast near the east mouth of the bay. In Kurosaki, starfish were collected from subtidal rocks shallower than $1 \mathrm{~m}$ deep during 9 visits between April 1998 and March 1999. In Uozu, samples were collected from boulders at a depth of $3 \mathrm{~m}$ while SCUBA diving during 16 visits between April 1998 and December 1999. The mean numbers of starfish collected were 14.9 at Kurosaki (range: 8 - 19) and 16.5 at Uozu (range: 11 27). Specimens were kept in a cooler and transported to the laboratories at Toyama University or Toyama Prefectural Fisheries Research Institute within two hours after collection. After recording the arm number and lengths of all arms (measured from the center of the mouth to the tip of each arm), the wet body weight (not eviscerated) and gonad weight were measured to calculate the gonad index (GI: total gonad weight / wet body weight $\times 100$ ) for every starfish collected. Using the arm length data, the ratio of regenerating arm length ( $r e$ ) to maximum arm length $(R)$ was calculated as an indicator of how recently fission occurred (a low $r e / R$ ratio indicates that fission recently occurred). The sex and developmental stage of gonads were determined by the following histological examination. Gonads dissected from the longest arm were fixed in Bouin's solution, dehydrated in alcohol, and embedded in paraffin wax. Sections measuring $6 \mu \mathrm{m}$ in thickness were cut and stained with Delafield's hematoxylin and eosin.

\section{RESULTS}

\section{Configurations of arm number}

Configurations of arm number of C. acutispina from the Kurosaki and Uozu populations are summarized in Table 1. A total of $95.6 \%$ of starfish from the Kurosaki population and $87.4 \%$ from the Uozu population had a set of long arms and a set of shorter regenerating arms, indicating that fission had occurred. The most frequent arm pattern was a combination of 4 long arms and 4 short arms, indicating that fission was most of ten symmetrical.

\section{Monthly change of gonad index}

Monthly changes in the gonad indices in the Kurosaki and Uozu populations are shown in Fig. 1 and Fig. 2, respectively. The Kurosaki population showed a distinct annual cycle of sexual reproduction (Fig. 1). Mean gonad indices of males were below 0.20 from April to October, then increased to a maximum of 3.89 in December (one sample measured 16.41). In females, the mean gonad indices increased in October, reaching a maximum of 6.52 in November, and then decreased gradually to near 0 in February.

In contrast, the mean gonad indices in the Uozu population remained below 0.06 throughout the study period (Fig. 2). The highest individual gonad index was 0.37 recorded in November and December 1998. The gonad indices of males and females (Fig. 2) were combined because few starfish (presumably males, see

Table 1. Percentage distribution of various arm configurations in Kurosaki and Uozu populations of Coscinasterias acutispina. "Individuals that have fully recovered from fission and thus have arms of equal length.

\begin{tabular}{|c|c|c|c|c|c|c|c|c|c|c|c|c|c|c|c|c|c|c|c|c|c|c|c|}
\hline \multirow{3}{*}{$\begin{array}{l}\text { Number of } \\
\text { short arms }\end{array}$} & \multicolumn{3}{|c|}{ Kurosaki } & & & & & & \multicolumn{3}{|c|}{$(n=134)$} & \multicolumn{9}{|c|}{ Uozu } & \multicolumn{3}{|c|}{$(n=264)$} \\
\hline & & \multicolumn{10}{|c|}{ Number of long arms } & \multirow{2}{*}{$\begin{array}{l}\text { Number of } \\
\text { short arms }\end{array}$} & & \multicolumn{10}{|c|}{ Number of long arms } \\
\hline & & 1 & 2 & 3 & 4 & 5 & 6 & 7 & 8 & 9 & 10 & & & 1 & 2 & 3 & 4 & 5 & 6 & 7 & 8 & 9 & 10 \\
\hline & Symmetrical ${ }^{*}$ & & & & & & & & 2.2 & 1.5 & 0.7 & & Symmetrical ${ }^{*}$ & & & & & & 0.8 & 1.1 & 7.6 & 2.7 & 0.4 \\
\hline 0 & & & & & 3.0 & 3.0 & & & & & & 0 & & & & & 4.5 & 0.4 & & & & & \\
\hline 1 & & & & & & & & & & & & 1 & & & & & 0.4 & & & 0.8 & 0.4 & & \\
\hline 2 & & & & & & & & 0.7 & & & & 2 & & & & & & 0.4 & 1.1 & & & & \\
\hline 3 & & & & 0.7 & 2.2 & & & & & & & 3 & & & & & 1.1 & 2.3 & & & & & \\
\hline 4 & & & 0.7 & 2.2 & 37.32 & 20.1 & 3.0 & & & & & 4 & & & 1.1 & 2.3 & 49.41 & 11.0 & & & & & \\
\hline 5 & & & & 2.2 & 11.9 & 3.0 & 0.7 & & & & & 5 & & & 0.8 & 3.0 & 6.8 & 0.8 & & & & & \\
\hline 6 & & & & & 0.7 & & & & & & & 6 & & & 0.4 & & & & & & & & \\
\hline 7 & & 0.7 & 1.5 & & & & & & & & & 7 & & & & & & & & & & & \\
\hline 8 & & 0.7 & & 0.7 & & & & & & & & 8 & & & & & & & & & & & \\
\hline 9 & & & & & & & & & & & & 9 & & 0.4 & & & & & & & & & \\
\hline
\end{tabular}


below) had developed gonads in which sex could be determined.

\section{Histological observation}

The developmental stages of gonads were classified into the following five stages;

Undeveloped stage: The follicular cavity is empty. Gonial cells are absent or when present, the sex can not be determined.

Growth stage: In females, the ovary contains small oocytes (about $10 \mu \mathrm{m}$ in diameter) attached to the follicular wall (Fig. 3A). In males, the follicular wall of the testis is lined with several layers of spermatogonia (about $10 \mu \mathrm{m}$ ), and sometimes spermatocytes were present (Fig. 3B).

Pre-mature stage: In females, pear-shaped oocytes (about $50-100 \mu \mathrm{m}$ ) are separated from the follicular wall, and occupy the lumen (Fig. 3C). In males, spermatocytes are abundant, forming a tube-like structure toward the central part of the lumen (Fig. 3D).

Mature stage: In females, the follicular lumen is filled with a large number of oocytes (about $80-150 \mu \mathrm{m}$ ) (Fig. 3E). In males, the entire space of the follicular lumen is largely filled with numerous spermatozoa (Fig. 3F).

Spent stage: In females, the lumen of the ovary is nearly empty with a few remnant oocytes present (Fig. $3 G$ ). In males, empty space occurs in the lumen of the testis, and some remnant spermatozoa remain (Fig. $3 \mathrm{H})$.

Fig. 4 shows the percent frequencies of the gonad stages (excluding undeveloped stage) in the Kurosaki population. Mature stages were found in gonads with gonad indices from 0.53 to 10.57 in males and from 0.23 to 16.41 in females. From April to August, all testes and ovaries were in the growth stage. In October, 66.7\% of males were in the pre-mature stage, and all females were in the pre-mature or mature stages. All testes were in the mature stage in November and December. After that, the frequency of spent testes increased, while mature stages of males were present until March. In females, the frequency of mature ovaries reached a maximum of $86.7 \%$ in November, decreased in December and January, and disappeared in February. These observations indicate that spawning of the Kurosaki population occurred in winter, namely, from November to March for males and from October to January for females.

On the contrary, no ovaries were recognized in histological observations on the gonads of 69 starfish
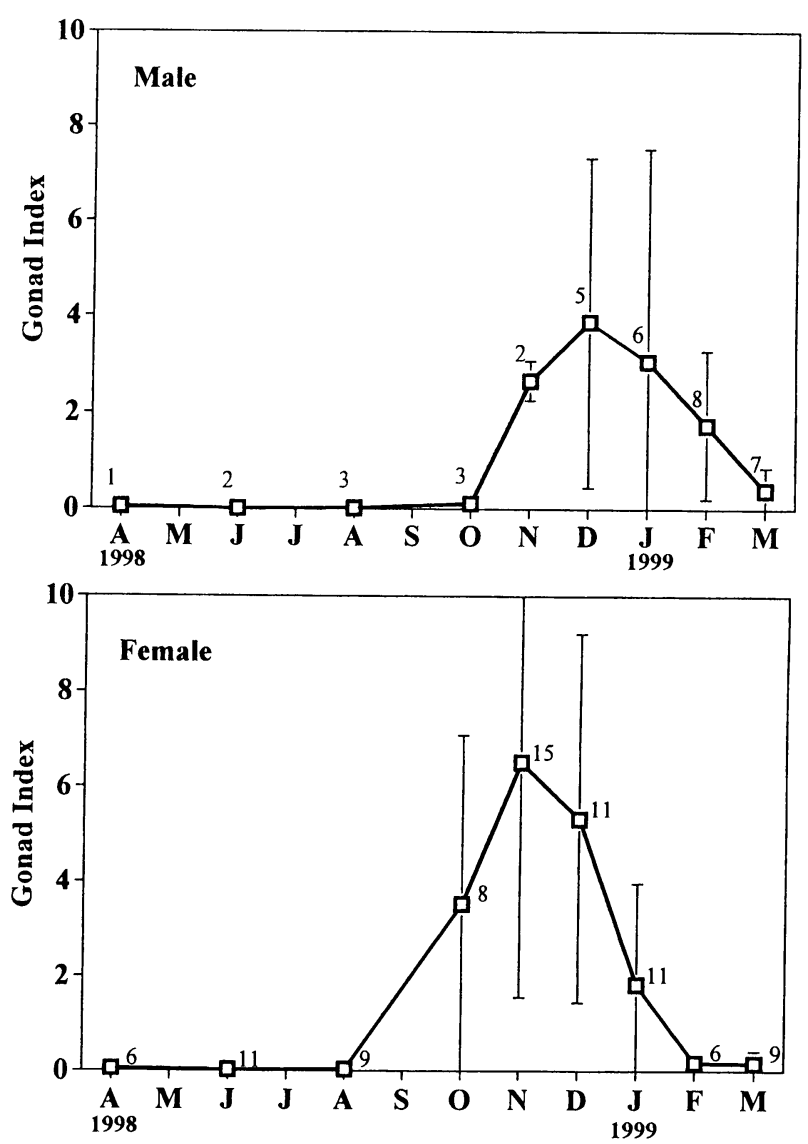

Fig. 1. Monthly changes of mean gonad index in the Kurosaki population of Coscinasterias acutispina. Vertical bars represent standard deviations. Numbers above date points indicate number of samples examined each month.

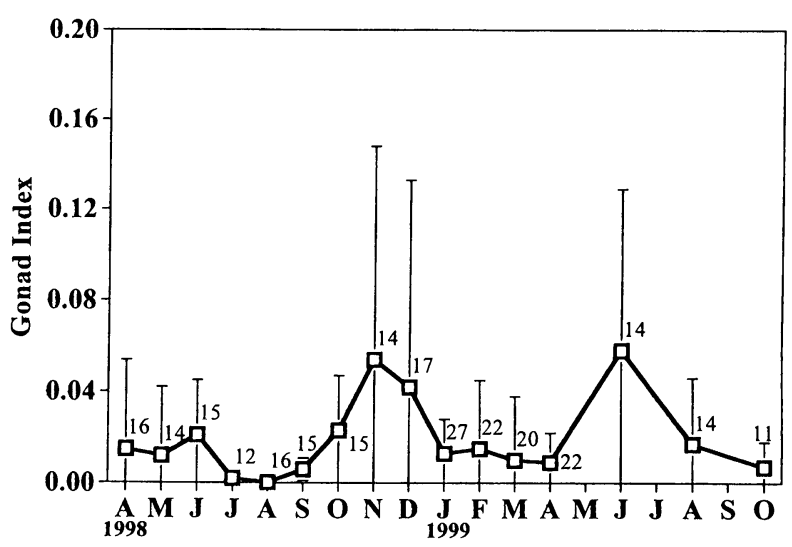

Fig. 2. Monthly changes of mean gonad index in the Uozu population of Coscinasterias acutispina (combined male and female values). Numbers above date points indicate number of samples examined each month. Vertical bars represent standard deviations. 
Seto et al.
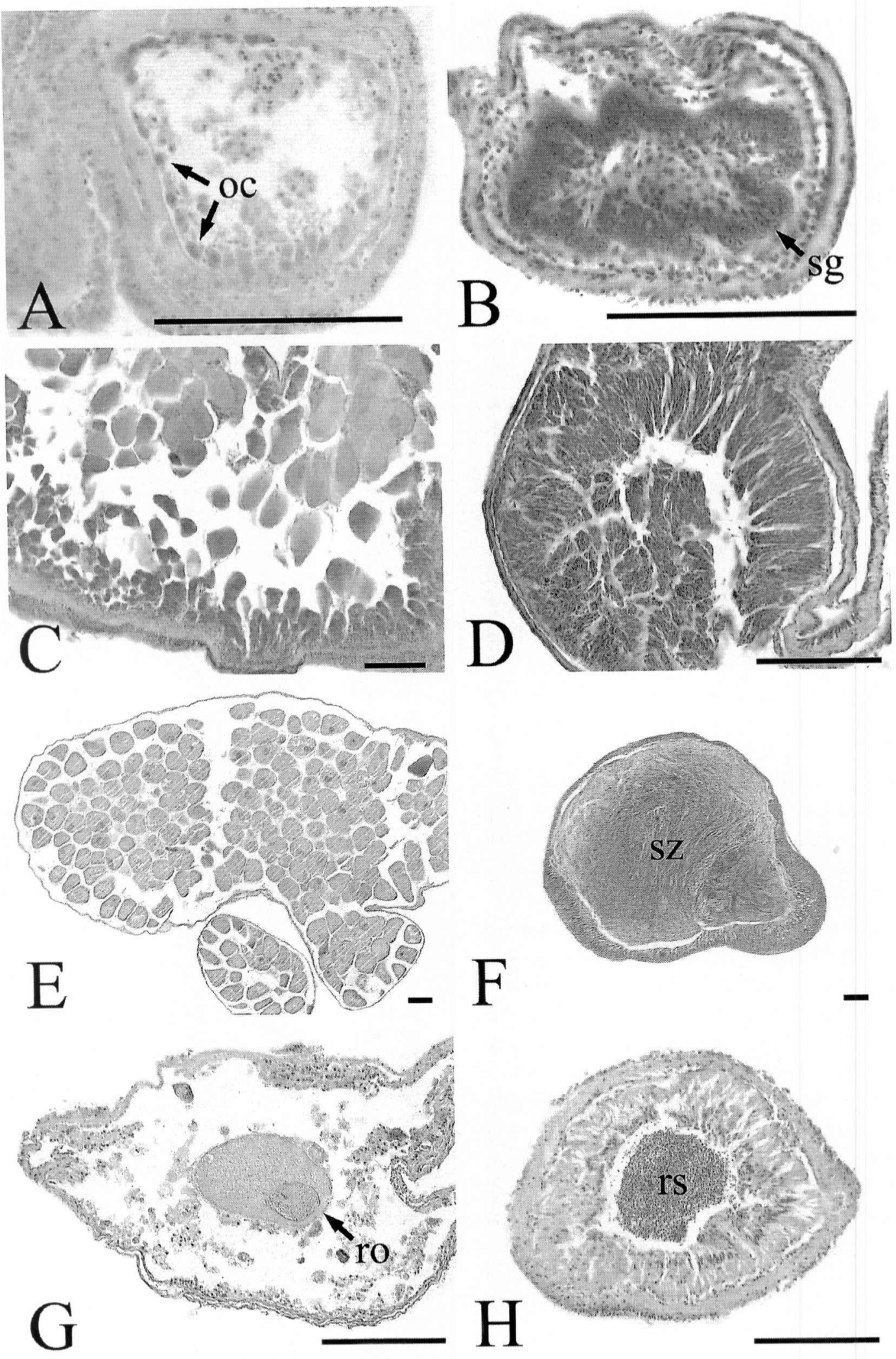

Fig. 3. Photomicrographs of the different stages of gonad development. A: Growth stage of ovary; B: Growth stage of testis; C: Pre-mature stage of ovary; D: Pre-mature stage of testis; E: Mature stage of ovary; F: Mature stage of testis; G: Spent stage of ovary; H: Spent stage of testis. oc: oocyte; sg: spermatogonium; sz: spermatozoa; ro: remnant oocyte; rs: remnant spermatozoa. Scale bars $=100 \mu \mathrm{m}$ 
from the Uozu population, which were collected in November 1998, January 1999, June 1999 and August 1999; 55 of the starfish were male and the other 14 were of indeterminate sex. In the 55 males, all testes were in the growth or pre-mature stage; slightly high values of GI 0.054 and 0.058 were recognized in November 1998 and June 1999, respectively (Fig. 2).

\section{Sex ratio}

The sex ratios in the Kurosaki and Uozu populations are shown in Table 2. Of the 134 starfish examined from the Kurosaki population, 37 were male, 86 were female and 11 were of indeterminate sex. On the other hand, the Uozu population was completely dominated by males; of the 75 starfish in which sex was examined, 60 were males, only 1 was female and 14 were of indeterminate sex.

\section{Asexual reproduction by fission}

Monthly changes in the ratio of regenerating arm length ( $r e$ ) to maximum arm length $(R)$ are shown in Fig. 5. In the Kurosaki population, the lowest re/ $R$ ratio class (i.e., $0-0.1$ ), which comprises starfish that have recently undergone fission, was observed from August to November. After the peak of this lowest class in October, the mode of the re/R ratio increased gradually, indicating the regeneration of short arms. In the Uozu population, the $0-0.1 \mathrm{re} / R$ ratio class was observed from June to December, with the peak occurring in July.

Size at sexual and asexual reproduction

Maximum arm length in the Kurosaki and Uozu populations ranged from 10 to $85 \mathrm{~mm}$ and from 12 to $91 \mathrm{~mm}$, respectively. Among them, the maximum arm length of starfish (Kurosaki population) in which maturity was recorded (i.e., with mature or spent stage of gonads, see below) ranged from 13.5 to $83 \mathrm{~mm}$ in males, and 15 to $73 \mathrm{~mm}$ in females. On the contrary, the maximum arm length of starfish that had undergone recent fission (i.e., re $/ R<0.1$ ) were 24 to $66 \mathrm{~mm}$ in the Kurosaki population and 25 to $73 \mathrm{~mm}$ in the Uozu population.
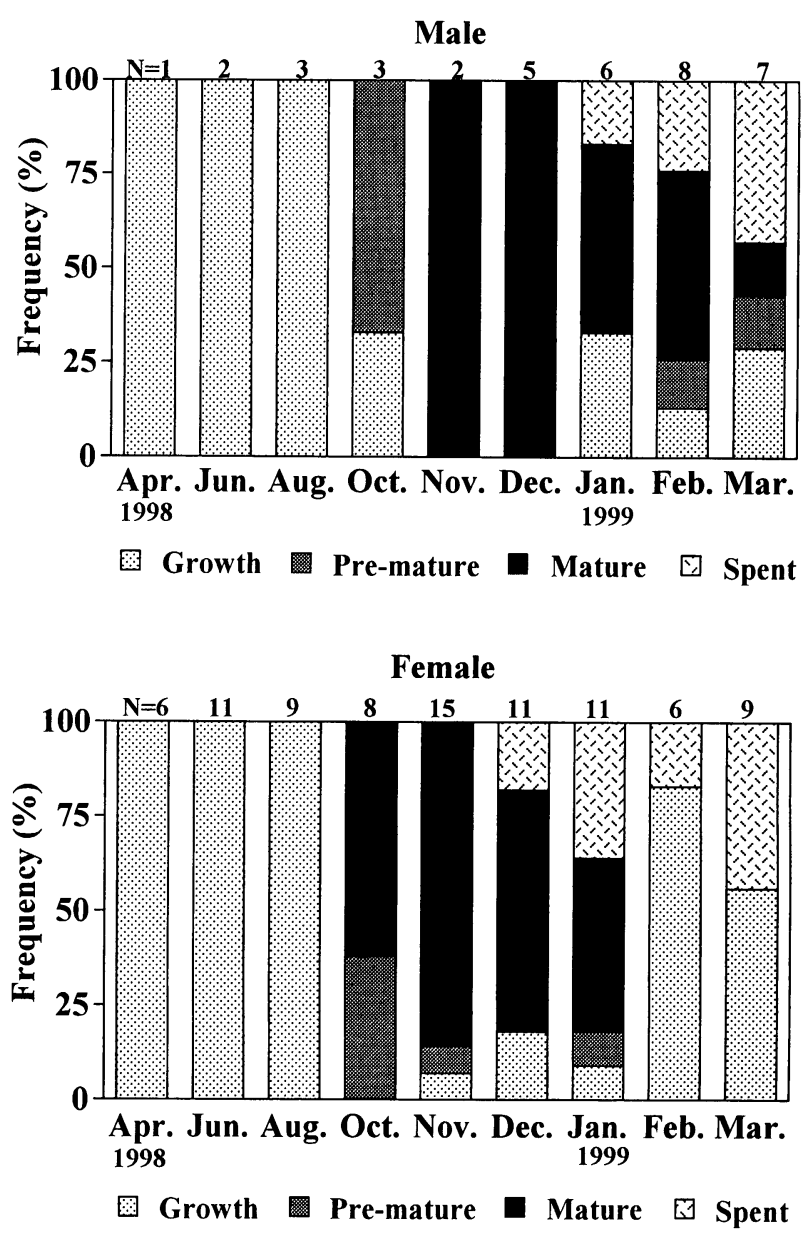

Fig. 4. Frequency of gonad stages in the Uozu population of Coscinasterias acutispina. Numbers above columns indicate the numbers of individuals examined each month.

\section{Mixture of sexual and asexual reproduction}

In 31 starfish of the Kurosaki population examined from October to November 1998, 5 showed signs of recent fission (i.e., $r e / R<0.1$ ) and had pre-mature or mature stages in their gonads. In addition, gonad indices of 3 starfish were as high as 1.71 to 8.40. These data demonstrated that asexual reproduction does not inhibit sexual reproduction.

Table 2. Sex ratios in the Kurosaki and Uozu populations of Coscinasterias acutispina.

\begin{tabular}{lcccccc}
\hline \multicolumn{1}{c}{ Site } & $n$ & Male & Female & $\begin{array}{c}\text { Sex } \\
\text { indeterminate }\end{array}$ & $\begin{array}{c}\text { Significant } \\
\text { difference } \\
1: 1 \text { ratio }\end{array}$ \\
\hline Kurosaki & 134 & 37 & 86 & 11 & 19.5 & $p<0.001$ \\
Uozu & 75 & 60 & 1 & 14 & 57.1 & $p<0.001$ \\
\hline
\end{tabular}



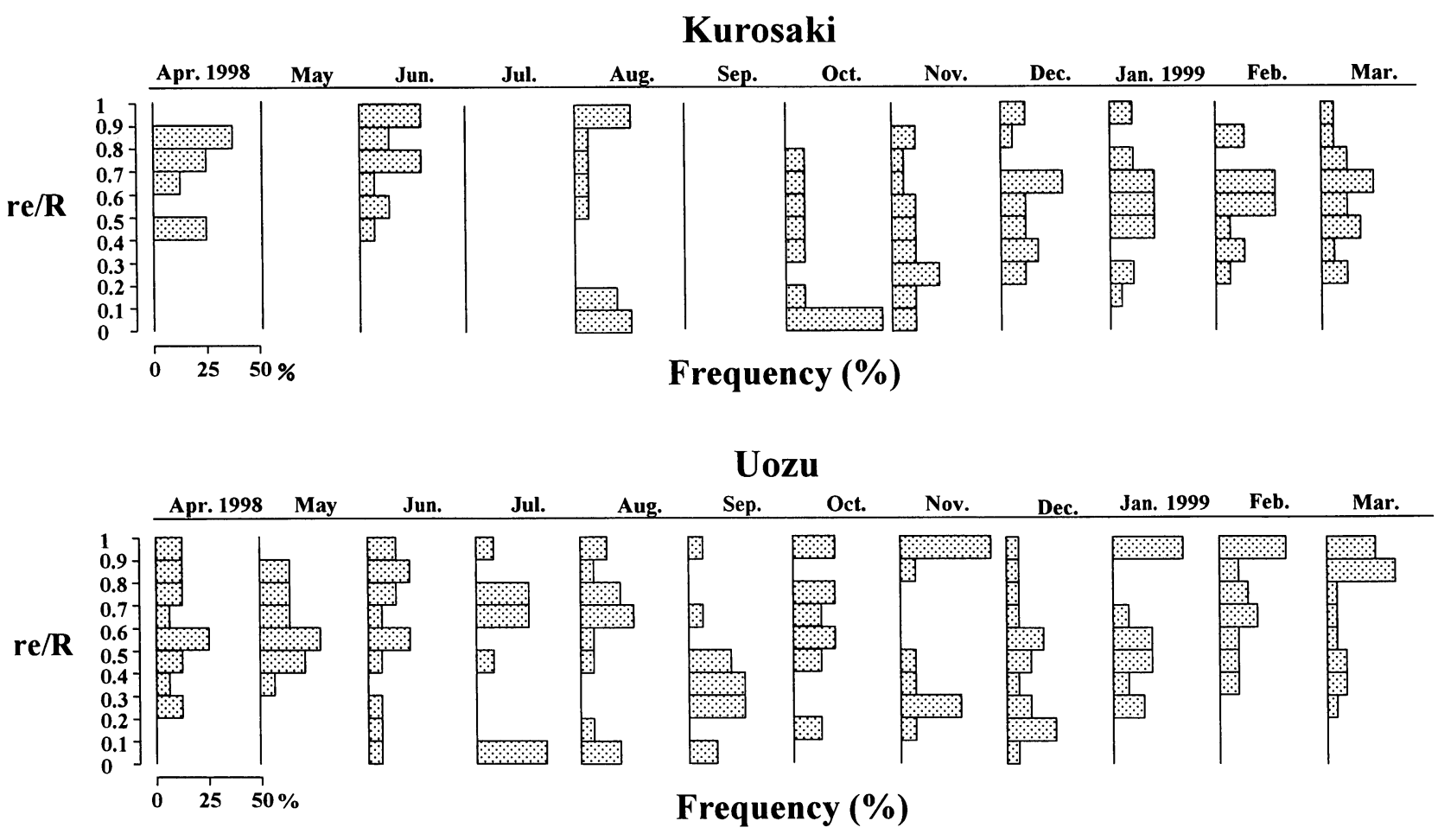

Fig. 5. Frequency of the ratio of $r e / R$ (= regenerating arm length $(r e) /$ maximum arm length $(R)$ ) combined in 0.1 blocks in the Kurosaki and Uozu populations.

\section{DISCUSSION}

Asexual reproduction by fission, as reported previously (Yamazi 1950; Fujita \& Seto 1998; T. Fujita 1999), was recognized in the two populations of Coscinasterias acutispina observed in the present study (Table 1, Fig. $5)$. Asexual reproduction was frequent from early summer to early winter in both populations, although the peak period varied somewhat in the two populations (Fig. 5). The present results agree with the results obtained during July to November from reared starfish collected from Uozu (Fujita \& Seto 1998).

A marked difference in sexual reproduction occurred in the two populations of Toyama Bay. In the Kurosaki population, gonad development (Fig. 3) exhibited a distinct annual cycle, with the breeding season occurring from October to March, namely, from November to March in males and from October to January in females (Fig. 1, Fig. 4). This result confirms the previous comment by Oguro \& Komatsu (1984) that the breeding season of C. acutispina in Toyama Bay occurs in winter. On the other hand, in the Uozu population, the gonad index was quite low throughout the year
(Fig. 2), and no starfish with mature gonads were ever found during the study. In addition, the sex ratio was extremely biased toward males (Table 2). These are new findings on the reproductive biology of $C$. acutispina, suggesting the absence of sexual reproduction and the low level or absence of larval recruitment in the population. This is the probable cause for the strong bias toward males in this population.

In Table 3 , information on the seasonality of sexual and asexual reproduction as well as feeding activity (Fujita \& Seto 1998) are summarized. The asexual reproductive season (from early summer to early winter) in Toyama Bay largely coincided with previous results from the Pacific coast of Japan, i.e. 'summer around September' in Sagami Bay (T. Fujita 1999) and 'spring to autumn' around the Kii Peninsula (Yamazi 1950). Splitting by fission in summer is advantageous for this warm temperate species, because the high feeding activity in higher summer sea temperatures (Fujita \& Seto 1998) may maximize the rates of regeneration, thereby decreasing the recovery time and thus the interval between subsequent fissions, as pointed out in a review (Mladenov \& Burke 1994). The prolonged asexual reproductive season around summer (present study) may be 
caused by repeated fission in the same individuals, as demonstrated in a rearing experiment (Fujita \& Seto 1998).

In the Kurosaki population, the peak of the asexual reproductive season preceded the peak of the sexual reproductive season by a few months (Table 3 ). Consequently, the breeding season (October to March) in Toyama Bay (Oguro \& Komatsu 1984; present study) was several months behind the breeding season (June to July) in Sagami Bay (Noumura \& Kanatani 1962) on the Pacific coast of central Japan. The reason for this difference is unknown, but winter surface water tem- peratures in Toyama Bay were $5{ }^{\circ} \mathrm{C}$ lower than in Sagami Bay (National Astronomical Observatory 1999) and may have contributed to the delay.

The size ranges of sexually and asexually reproducing starfish are summarized in Table 4. In the Kurosaki population, the size range of sexually reproductive starfish (i.e., mature or spent stage in histological observation) included nearly all sizes of starfish collected, and the size range of asexually reproducing starfish was somewhat narrower than that of sexually reproducing ones. Y. Seto (unpublished data) found starfish as small as $6 \mathrm{~mm}$ in maximum arm length that appeared

Table 3. Seasonality of asexual and sexual reproduction and feeding activity of Coscinasterias acutispina in Japan. @: Peak. $\bigcirc$ : High or common. $\triangle:$ : Low or present. a: Underlined months include repeated fission. b: Underlined months were supplemented with unpublished data by Y. Seto.

\begin{tabular}{|c|c|c|c|c|c|c|c|c|c|c|c|c|c|c|}
\hline & & & & & & & & & & & & & & \\
\hline & Locality & A & $\mathrm{M}$ & $\mathrm{J}$ & $\mathrm{J}$ & A & $\mathrm{S}$ & 0 & $\mathrm{~N}$ & $\mathrm{D}$ & $\mathrm{J}$ & $\mathrm{F}$ & $\mathrm{M}$ & Reference \\
\hline Asexual reproduction & Kurosaki & & & & & O & & (2) & $\triangle$ & & & & & Present study \\
\hline & Uozu & & & $\triangle$ & (0) & 0 & & & & $\triangle$ & & & & Present study \\
\hline & Uozu & & & & $\bigcirc$ & 0 & O & $\underline{0}$ & 0 & & & & & Fujita \& Seto (1998) \\
\hline & Hayama & & & $\triangle$ & O & () & (-) & (?) & O & O & $\triangle$ & & & T. Fujita（1999） \\
\hline Sexual reproduction & Kurosaki $\left(\sigma^{7}\right)$ & & & & & & & & () & () & $\bigcirc$ & 0 & $\triangle$ & Present \\
\hline & Kurosaki (ㅇ) & & & & & & & 0 & () & O & $\triangle$ & & & Present study \\
\hline Feeding activity & Uozu & $\triangle$ & $\triangle$ & (0) & (2) & () & 0 & 0 & $\triangle$ & $\triangle$ & $\triangleq$ & $\triangle$ & $\triangle_{\mathrm{b}}$ & Fujita \& Seto (1998) \\
\hline
\end{tabular}

Table 4. Size ranges of sexually and asexually reproducing Coscinasterias acutispina in Japan. Note that data of Fujita \& Seto (1998) were obtained from a rearing experiment, while the others were from measurements of field collections.

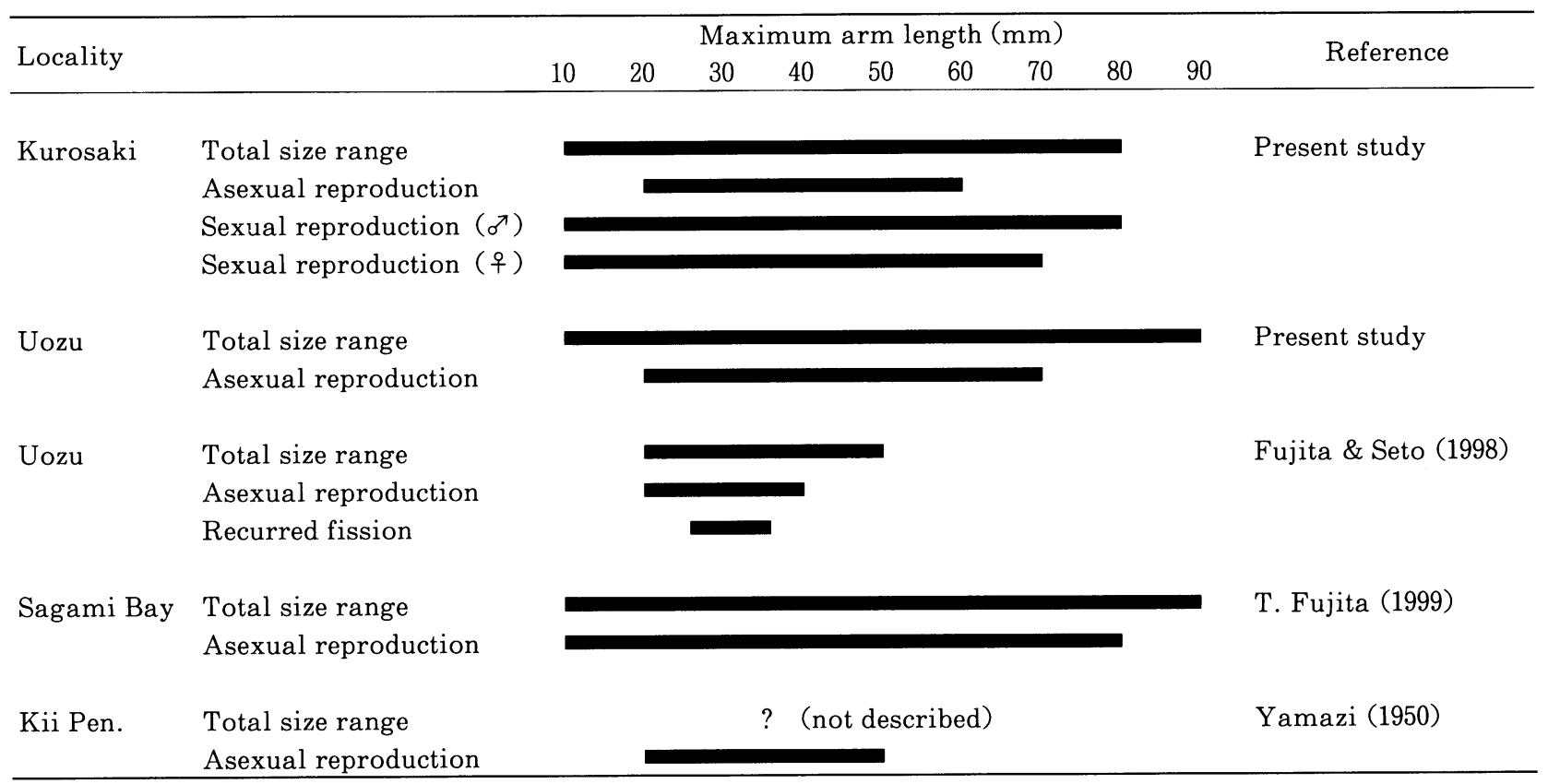


to have undergone asexual reproduction. These data suggest that sexual reproduction occurs throughout the life of the starfish while asexual reproduction occurs in juveniles and intermediate-size individuals. The limited size range (small to middle) of asexually reproducing starfish has also been noted in population at Sagami Bay (T. Fujita 1999), Kii Peninsula (Yamazi 1950) and Uozu (present study). The dominant occurrence of asexual reproduction in smaller 'juvenile' members of a population is common in fissiparous asteroids (Mladenov \& Burke 1994). However, it is very difficult to discuss its ecological importance until data on growth and regeneration rates after fission, and longevity are obtained.

As discussed above, absence of sexual reproduction in a population (Uozu) was strongly suggested in the present study. Similar examples in some fissiparous asteroids reviewed in Mladenov \& Burke (1994) varied from obligatory fissiparous to locally facultative. For example, Stephanasterias albula (Stimpson) is an obligatory fissiparous species in which there is no trace of differentiated reproductive system and of associated aboral haemal and coelomic rings (Mladenov et al. 1986). In a Mediterranean population of Asterina burtoni Gray, only the testes were detected, and spermatogenesis followed an annual pattern, while sexual reproduction occurred in the Red Sea (Achituv \& Sher 1991). The Uozu population of C. acutispina appears to be another type in which males were dominant, but their gonads poorly developed. Low gonad indices and a preponderance of males were also noted in a population (Aquarium Point) of the closely related species, $C$. muricata Verrill (as C. calamaria) (Crump \& Barker 1985). Environmental factors (e.g., food supply and physical stress, such as water temperature and wave condition) and genetic factors are thought to be the reason(s) for the absence of sexual reproduction in the Uozu population. Recently, starfish with high gonad indices $(>10)$ were found from a neighboring population at Namerikawa, $10 \mathrm{~km}$ west of Uozu (Y. Seto, unpublished data). The presence of mature starfish in a neighboring population which has similar environmental conditions to those at Kurosaki and extremely biased sex ratios toward males (Table 2) suggest that genetic factors may be the cause for the absence of sexual reproduction in the Uozu population. Therefore, further approaches using population genetics are needed to evaluate the contributions of clonal and sexual reproduction, as has been done in C. muricata (as $C$. calamaria) (Johnson \& Threlfall 1987).
Acknowledgments. We are grateful to Dr. Chitaru Oguro, Professor emeritus of Toyama University, and to Dr. Mike Barker, Professor of University of Otago for their useful advice and constructive criticism.

\section{REFERENCES}

Achituv, Y. and E. Sher 1991. Sexual reproduction and fission in the sea star Asterina burtoni from the Mediterranean coast of Israel. Bulletin of Marine Science, 48: 670-768.

Crump, R. G. and M. F. Barker 1985. Sexual and asexual reproduction in geographically separated populations of the fissiparous asteroid Coscinasterias calamaria (Gray). Journal of Experimental Marine Biology and Ecology, 88: 109-127.

Fujii, A. 1991. Predation on young topshell, Batillus cornutus, by carnivorous marine animals. Suisanzoshoku, 39: 123-128 (in Japanese).

Fujita, D. and Y. Seto 1998. On a sea star Coscinasterias acutispina (Asteroidea, Asteriidae) in Toyama Bay (Preliminary Report). Bulletin of Toyama Prefectural Fisheries Research Institute, 10: 53-64 (in Japanese).

Fujita, D. and Y. Seto 2000a. Distribution of a fissiparous multi-armed sea star, Coscinasterias acutispina in Japan. Bulletin of Toyama Prefectural Fisheries Research Institute, 12: 19-31 (in Japanese).

Fujita, D. and Y. Seto 2000b. Notes on released abalone in Uozu City, Toyama Prefecture. Bulletin of Toyama Prefectural Fisheries Research Institute, 12: 13-18 (in Japanese).

Fujita, T. 1999. Population structure of a fissiparous sea star Coscinasterias acutispina. In, Echinoderm Research 1998, Carnevali, C. and F. Bonasoro (eds.), Balkema, Rotterdam, pp. 465-470.

Futashima, K., T. Ito and O. Ezaki 1989. Study on development of technologies in marine cultivation of several beneficial algal animals - II : On way to release of young abalone Haliotis discus. Bulletin of Fukuoka Prefectural Fukuoka Fisheries Experimental Station, 15: 33-45 (in Japanese).

Hayashi, I. 1988. Habitat preference, diurnal activity pattern and predators of the artificially bred juvenile abalone Haliotis discus discus. Venus, 47: 104-120 (in Japanese).

Iwasaki, K. 1993. Analyses of limpet defense and predator offence in the field. Marine Biology, 116: 277-289.

Johnson, M. S. and T. J. Threlfall 1987. Fissiparity and population genetics of Coscinasterias calamaria. Marine Biology, 93: 517-525. 
Mladenov, P. V. and R. D. Burke 1994. Echinodermata: Asexual reproduction. In: Reproductive Biology of Invertebrates, Adiyodi, K. G. and R. G. Adiyodi (eds.), Oxford \& IBH Publishing Co. Pvt. Ltd., New Delhi, pp. 339-383.

Mladenov, P. V., S. F. Carson and C. W. Walker 1986. Reproductive ecology of an obligately fissiparous population of the sea star Stephanasterias albula (Stimpson). Journal of Experimental Marine Biology and Ecology, 96: $155-175$

National Astronomical Observatory (ed.) 1999. Rika Nenpyo (Chronological Scientific Table). Maruzen Co. Ltd., Tokyo, 688 pp.
Noumura, T. and H. Kanatani 1962. Induction of spawning by radial nerve extracts in some starfishes. Journal of the Faculty of Science, Tokyo University, 9: 397- 402. Oguro, C. and M. Komatsu 1984. Reproduction and development of sea stars I. Aquabiology, 30: 24-32 (in Japanese).

Yamazi, I. 1950. Autotomy and regeneration in Japanese sea-stars and ophiurans. I : Observation on a sea-star Coscinasterias acutispina Stimpson and four species of ophiurans. Annotationes Zoologicae Japonenses, 23: 175-186. 